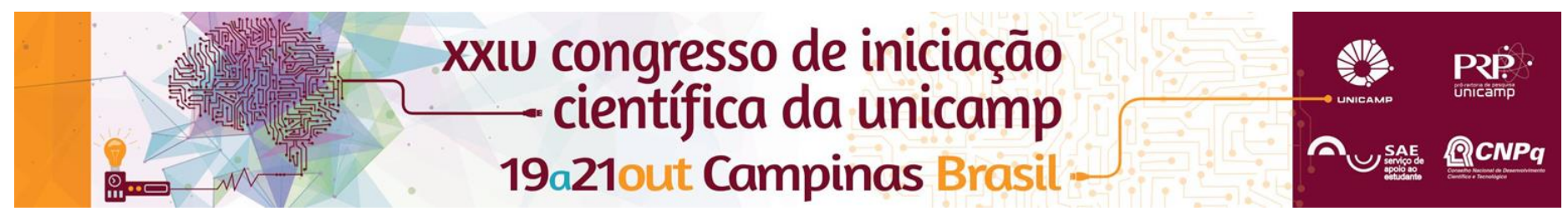

\title{
ANÁLISE DE OCUPAÇÃO DE TERRITÓRIO PÚBLICO - CEU (Centro de Artes e Esportes Unificados) - Limeira/SP - Jovens
}

\section{Ana Ribeiro Neves*}

\section{Resumo}

Essa Iniciação Científica vem sendo realizada em conjunto com o PTS (Projeto Técnico Social) que existe desde 2014. Tem o objetivo de analisar a ocupação do território do CEU (Centro de Artes e Esportes Unificados) que abriga um Centro de Referência de Assistência Social e se localiza na periferia da cidade, e onde o PTS realiza oficinas desde o início de 2016. A pesquisa é focada na ocupação do local por jovens e busca entender a relação dessas pessoas com o espaço em questão. É realizada por meio de entrevistas semiestruturadas e relatos de atividades realizadas no local.

Palavras-chave:

Território, Pertencimento, Ocupação.

\section{Introdução}

Em 2014 teve início a obra de um reservatório de água na cidade de Limeira que é realizada por meio do PAC-2 do governo federal. A obra é acompanhada do Projeto Técnico Social, no qual um grupo de sete alunos da Unicamp trabalha juntamente com o Ceproson, órgão vinculado à prefeitura, e atualmente também com o Senac. Foi acordado que nesse projeto o papel da Unicamp seria promover ações e pesquisas voltadas para as áreas de Educação Socioambiental e Educomunicação.

Devido a isso oficinas com essas temáticas vêm sendo realizadas em centros comunitários e escolas públicas desde o início do projeto, com o objetivo de gerar consciência individual e coletiva nos participantes a respeito de temas voltados principalmente à educação ambiental. Desde o início de 2016 essas atividades passaram a ser realizadas no CEU (Centro de Artes e Esportes Unificados) com um grupo de jovens de até 18 anos e é nesse cenário que essa pesquisa se desenvolve.

A Iniciação Científica busca levantar dados de como ocorre a ocupação desse espaço pelos jovens e como o sentimento de pertencimento influencia essa ocupação. Segundo Marcos Sorrentino, mestre em educação pela Universidade Federal de São Carlos, a compreensão do pertencimento possibilita uma potência no sentido da transformação, uma possibilidade maior de interferir positivamente no seu espaço.

Dessa forma a pesquisa tem se desenvolvido em parte junto com as oficinas semanais realizadas pela Unicamp no CEU, com o grupo de jovens, nas quais temáticas como território, pertencimento e espaço público vem sendo tratadas.

\section{Resultados e Discussão}

Durante o início do ano realizou-se um levantamento bibliográfico que criou uma base de dados mais rica a respeito de processos de ocupação de espaços públicos, pertencimento e juventude. Essas leituras contribuíram para o embasamento teórico da pesquisa que seria conduzida nas próximas etapas.
A partir de entrevistas semiestruturadas e do registro das oficinas que vem ocorrendo espera-se levantar dados sobre como os jovens utilizam o espaço do CEU e o que ele representa no dia a dia dessa parcela da população. Também serão entrevistadas pessoas que participaram da organização de eventos voltados para os jovens e a partir dessas entrevistas espera-se descobrir os motivos e objetivos das pessoas que se envolvem nessas organizações.

De acordo com o estudo: Juventude, Violência e Vulnerabilidade Social na América Latina: Desafios para Políticas Públicas, a cultura de rua pode ser uma saída alternativa para um cenário de violência. Sendo assim espera-se também descobrir se o CEU influencia de forma positiva a população no sentido de desviar os jovens de um cenário de violência.

No final dessa pesquisa espera-se desenvolver um estudo consistente do processo de ocupação por jovens do CEU e relacionar a ocupação com o sentimento de pertencimento.

\section{Conclusão}

Por conta da pesquisa ainda não ter sido finalizada a conclusão ainda se encontra em aberto.

\section{Agradecimentos}

Agradeço o professor Dr. Sandro Tonso pela oportunidade de realizar a pesquisa, o grupo de trabalho do PTS, a Caixa Econômica Federal pelo suporte financeiro e os jovens participantes das oficinas do CEU.

\footnotetext{
${ }^{1}$ ABRAMOVAY, M., CASTRO, M., PINHEIRO,L., (...) "Juventude, Violência e Vulnerabilidade Social na América Latina”, Edição UNESCO Brasil, (2002);

2 PREFEITURA MUNICIPAL DE LIMEIRA-PML (2014) - " Prefeitura apresenta CEU e inaugura Centro Comunitário neste domingo"- site oficial da Prefeitura de Limeira com notícias da cidade de Limeira, 2014.

$<$ http://serv90.limeira.sp.gov.br/pml/noticias/ceprosom/prefeitura-apresentaceuinaugura-centro-comunitario-neste-domingo $>$;
}

${ }^{3}$ SORRENTINO, Marcos (coord.). Ambientalismo e participação na contemporaneidade. São Paulo: EDUC/FAPESP, 2002. 